\title{
PERTUMBUHAN DAN PERKEMBANGAN IN VITRO JAMUR Beauveria bassiana MUTAN SERTA VIRULENSINYA TERHADAP HAMA PENGISAP POLONG KEDELAI (Riptortus linearis) DI LABORATORIUM
}

\author{
Lita Aprianda Sari ${ }^{1)}$, F.X. Susilo ${ }^{2)}$, Yuyun Fitriana ${ }^{2)}$, Lestari Wibowo ${ }^{2)}$ \\ ${ }^{1)}$ Mahasiswa dan ${ }^{2)}$ Dosen Jurusan Agroteknologi \\ Fakultas Pertanian Universitas Lampung \\ Jl. Prof. Dr. Sumantri Brojonegoro No. 1, Bandar Lampung 35145
}

\begin{abstract}
ABSTRAK
Penelitian ini bertujuan mengetahui pertumbuhan dan perkembangan in vitro jamur Beauveria bassiana mutan serta virulensinya terhadap hama pengisap polong kedelai, R. linearis. Penelitian dilakukan di Laboratorium Bioteknologi Pertanian Fakultas Pertanian Universitas Lampung dan dilaksanakan bulan Januari - Juni 2017. Uji pertumbuhan $B$. bassiana secara in vitro menggunakan Rancangan Acak Lengkap (RAL) dengan 3 perlakuan dan 5 ulangan. Uji virulensi jamur B. bassiana terhadap R. linearis menggunakan analisis probit. Virulensi diindikasikan dengan $\mathrm{LT}_{50}$ atau lethal time 50, yaitu waktu yang dibutuhkan jamur ini untuk mematikan $50 \%$ larva uji. Hasil penelitian menunjukkan bahwa isolat Bbyf22 dan Bbyf24 (mutan) mampu tumbuh dan berkembang dengan normal seperti isolat Bbyf (wildtype). Jamur B. bassiana terbukti virulen terhadap hama $R$. linearis dengan $\mathrm{LT}_{50}=3,7$ hari (isolat Bbyf22, mutan); 4,9 hari (isolat Bbyf24, mutan); dan 3,5 hari (isolat Bbyf, wildtype).

Kata kunci: Beauveria bassiana, pengisap polong kedelai, Riptortus linearis, virulensi.
\end{abstract}

\section{PENDAHULUAN}

Tanaman kedelai tidak luput dari serangan hama pengisap polong kedelai. Hama $R$. linearis penyebarannya cukup luas di Indonesia (Asadi, 2009). R. linearis dapat menyebabkan kegagalan panen hingga $80 \%$. Sebagian besar kerusakan yang terjadi dapat ditemukan pada bagian polong. Polong yang telah dihisap terlihat kempis, mengering, dan gugur. Apabila tidak dikendalikan maka populasi hama tersebut akan meningkat (Atman, 2012).
Pengendalian terhadap hama $R$. linearis selama ini lebih mengandalkan insektisida kimia. Penggunaan insektisida kimia secara terus-menerus menimbulkan berbagai dampak negatif. Dampak yang ditimbulkan pada pertanaman kedelai diantaranya ledakan populasi (resurgensi) R. linearis. Selain itu terjadinya resistensi $R$. linearis terhadap insektisida kimia tersebut dan terjadinya pencemaran lingkungan (Hasibuan, 2003).

Untuk menghindari efek negatif dari 
penggunaan pestisida kimia, perlu kiranya dicari alternatifpengendalian lainnya, misalnya menggunakan jamur entomopatogen. Beauveria bassiana dilaporkan sebagai jamur entomopatogen yang sangat efektif terhadap beberapa spesies serangga hama termasuk rayap, kutu putih, dan beberapa jenis kumbang (Soetopo \& Indrayani, 2007). Jamur entomopatogen ini diduga memiliki virulensi terhadap kepik.

Penelitian yang telah dilakukan oleh Avanti et al. (2014) menunjukkan jamur B. bassiana dapat dimutankan. Salah satu cara pemutanan adalah melalui proses moist heat dengan diinkubasi pada suhu $27^{\circ} \mathrm{C}$ selama $15-17$ hari. B. bassiana juga dapat dimutankan melalui proses penyinaran UV dibawah $254 \mathrm{~nm}$ pada media agar dan diinkubasi selama 8 hari. Teknologi mutasi menggunakan ion beam juga telah diterapkan pada B. bassiana (Fitriana et al., 2014).

Mutasi umumnya fatal namun ada mutan yang sintas. B. bassiana mutan misalnya, dapat bertahan hidup dan mampu beradaptasi dengan lingkungannya. Berdasarkan penelitian (Fitriana et al., 2014), jamur mutan B. bassiana lebih virulen terhadap hama. Namun sampai saat ini, isolat Bbyf hasil mutasi (Fitriana et al., 2014) belum diketahui kemampuannya terhadap kepik R. linearis.

\section{BAHAN DAN METODE}

Penelitian terdiri atas dua kegiatan. Kegiatan pertama ialah uji pertumbuhan dan perkembangan $B$. bassiana secara in vitro. Kegiatan ini mencakup pembiakkan jamur mutan B. bassiana, penumbuhan koloni $B$. bassiana, pengukuran kerapatan spora $B$. bassiana, dan uji viabilitas $B$. bassiana.Kegiatan kedua ialah uji virulensi $B$. bassiana terhadap $R$. linearis.

Pada penelitian ini dilakukan uji pertumbuhan dan perkembangan $B$. bassiana secara in vitro dengan 3 perlakuan dan 5 ulangan. Uji pertumbuhan dan perkembangan dilakukan dengan menumbuhkan jamur mutan B. bassiana pada media PDA. Pengukuran diameter jamur dilakukan setiap hari setelah inokulasi. Setelah 15 hsi, dihitung jumlah spora jamur mutan $B$. bassiana. Kemudian dilakukan uji viabilitas spora setelah diinkubasi selama 16 jam.

Uji virulensi menggunakan analisis probit. Ukuran probit yang digunakan yaitu $\mathrm{LT}_{50} . \mathrm{LT}_{50}$ adalah waktu yang dibutuhkan untuk mematikan 50\% larva uji. Pada penelitian ini, $\mathrm{LT}_{50}$ dihitung menggunakan program SPSS versi 24.

\section{HASIL DAN PEMBAHASAN}

Berikut di bawah ini diameter koloni jamur $B$. bassiana mulai 3 hingga 15 hsi (Gambar 2). Isolat jamur B. bassiana Bbyf22 dan isolat jamur B. bassiana Bbyf24 (mutan) mampu tumbuh normal. Pada hari ke3 sampai 11 hsi, diameter koloni isolat jamur $B$. bassiana Bbyf24 (mutan) bahkan nampak lebih besar daripada isolat jamur B. bassiana Bbyf(wildtype).

Diameter koloni isolat jamur B. bassiana Bbyf22 (mutan) dan Bbyf (wildtype) pada hari ke-3 sampai 11 hsi nampak tidak berbeda. Begitu juga pengamatan pada hari ke-13 sampai 15 tidak terlihat perbedaan yang signifikan. Ini membuktikkan bahwa isolat jamur B. bassiana mutan mampu survive seperti 


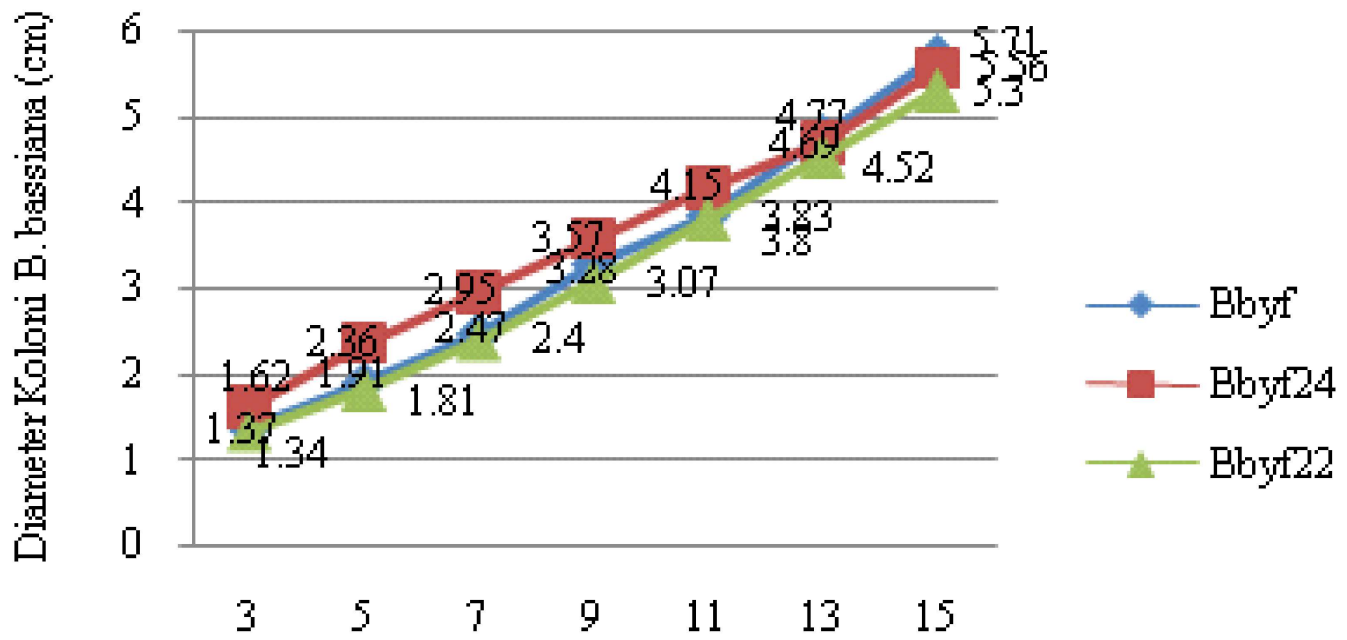

HariSetelah Irokulasi(hsi)

Gambar 2. Diameter koloni B. bassiana yang ditumbuhkan pada media PDA. (Bbyf $22=$ Isolat B. bassiana yang berasal dari iradiasi ion beam; Bbyf $24=$ Isolat $B$. bassiana yang berasal dari iradiasi ion beam; Bbyf = Isolat $B$. bassiana yang berasal dari larva kumbang Shizuoka; hsi = hari setelah inokulasi).

Tabel 2. Kerapatan spora jamur B. bassiana

\begin{tabular}{cc}
\hline Perlakuan & Kerapatan Spora B. bassiana $\left(\mathrm{x} 10^{6} / \mathrm{ml}\right)$ \\
\hline Bbyf22 (mutan) & 8,32 b \\
Bbyf24 (mutan) & 7,16 b \\
Bbyf(wildtype) & 16,08 a \\
\hline BNT 5\% & 4,49 \\
\hline
\end{tabular}

Keterangan : Angka-angka yang diikuti oleh huruf yang sama pada kolom yang sama menunjukkan tidak berbeda nyata (BNT 5\%). (Bbyf22 = Isolat $B$. bassiana yang berasal dari iradiasi ion beam; Bbyf 24 = Isolat $B$. bassiana yang berasal dari iradiasi ion beam; Bbyf= Isolat $B$. bassiana yang berasal dari larva kumbang Shizuoka).

isolat jamur B. bassiana wildtype. Berdasarkan hasil BNT 5\%, pada hari ke-13 dan 15 hsi isolat jamur $B$. bassiana Bbyf22 dan Bbyf24 (mutan) tidak berbeda nyata dengan isolat jamur B. bassiana Bbyf(wildtype) $\left(\mathrm{F}_{\text {hit }}=0,80^{\mathrm{tn}}\right)$.

Hasil perhitungan terlampir pada tabel 2, kerapatan spora jamur B. bassiana mutan dan wildtype.. Isolat jamur Bbyf22 dan Bbyf24 (mutan) menghasilkan spora yang relatif sama banyak. Isolat
Bbyf(wildtype) menghasilkan spora lebih banyak dari isolat Bbyf22 atau Bbyf24 (mutan).

Tabel 3 menunjukkan bahwa spora-spora jamur mutan mampu berkecambah dengan baik. Daya berkecambah spora isolat jamur mutan (Bbyf22 dan Bby24) tidak berbeda dengan daya berkecambah spora isolat jamur wildtype (Bbyf). Itu menunjukkan bahwa isolat jamur mutan (Bbyf22 dan Bbyf24) dapat sintas sebagaimana isolat jamur wildtype (Bbyf). 
Tabel 3. Daya berkecambah (viabilitas) spora jamur B. bassiana yang telah diinkubasi selama 16 jam pada media PDA

\begin{tabular}{cc}
\hline Perlakuan & Spora B. bassiana berkecambah (\%) \\
\hline Bbyf22 (mutan) & $78,20 \mathrm{a}$ \\
Bbyf24 (mutan) & $72,40 \mathrm{a}$ \\
Bbyf (wildtype) & $73,40 \mathrm{a}$ \\
\hline F $_{\text {hitung }}$ & 0,09 \\
\hline
\end{tabular}

Keterangan: Angka-angka yang diikuti oleh huruf yang sama pada kolom yang sama menunjukkan tidak berbeda nyata (Uji F 5\%). (Bbyf22 = Isolat B. bassiana yang berasal dari iradiasi ion beam;

Bbyf 4 = Isolat $B$. bassiana yang berasal dari iradiasi ion beam; Bbyf = Isolat B. bassiana yang berasal dari larva kumbang Shizuoka).

Tabel 4. $\mathrm{LT}_{50}$ tiga isolat jamur B. bassiana terhadap R. linearis

\begin{tabular}{cccc}
\hline \multirow{2}{*}{ Isolat } & \multicolumn{3}{c}{$\mathrm{LT}_{50}$ (hari) } \\
\cline { 2 - 4 } & Rata-rata & Minimal & Maksimal \\
\hline Bbyf24 (mutan) & $4,9 \mathrm{a}$ & 4,1 & 6,2 \\
Bbyf2 (mutan) & $3,7 \mathrm{ab}$ & 3,1 & 4,4 \\
Bbyf (wildtype) & $3,5 \mathrm{~b}$ & 3,1 & 3,9 \\
\hline
\end{tabular}

Keterangan: $\mathrm{LT}_{50}$ nyata pada taraf 5\%. Bbyf22 diinokulasikan pada kerapatan $8,32 \times 10^{6} / \mathrm{ml}$ (tidak berbeda nyata antar-isolat Bbyf), Bbyf24 diinokulasikan pada kerapatan 7,16 x 10\% $/ \mathrm{ml}$ (tidak berbeda nyata antar-isolat Bbyf22), dan Bbyf diinokulasikan pada kerapatan 16,08 x 10\%/ $\mathrm{ml}$ (tidak berbeda nyata antar-isolat Bbyf22).

Tabel 4 menyajikan $\mathrm{LT}_{50}$ isolat jamur mutan dan wildtype terhadap $R$. linearis. $\mathrm{LT}_{50}$ Bbyf (wildtype) tidak berbeda nyata dengan $\mathrm{LT}_{50}$ Bbyf22 (mutan). $\mathrm{LT}_{50}$ Bbyf22 (mutan) tidak berbeda nyata dengan $\mathrm{LT}_{50}$ Bbyf 24 (mutan). LT $_{50}$ Bbyflebih kecil dibandingkan $\mathrm{LT}_{50}$ Bbyf24 (wildtype). Itu menunjukkan menunjukkan bahwa isolat Bbyf (mutan) dan Bbyf22 (wildtype) mampu mematikan $R$. linearis $50 \%$ dalam waktu yang relatif sama.

\section{PEMBAHASAN}

Pertumbuhan dan perkembangan $B$. bassiana Bbyf22 dan Bbyf24 (mutan) tidak berbeda jauh dengan pertumbuhan dan perkembangan Bbyf(wildtype).
Dilihat dari data pengamatan pertumbuhan diameter (Gambar 2) dan perkecambahan sporanya (Tabel 3), isolat mutan mampu tumbuh dan berkembang dengan normal seperti isolat wildtype. Sebagaimana hasil penelitian Dwayne \& Khachatourians (1994), jamur B. bassiana dari hasil pemutanan sinar ultraviolet dapat menghasilkan konidia dengan daya berkecambah yang baik pada suhu $22-25^{\circ} \mathrm{C}$. Penelitian ini dilaksanakan pada suhu $20-25^{\circ} \mathrm{C}$.

Tabel 2 menunjukkan bahwa isolat jamur mutan menghasilkan kerapatan spora yang lebih sedikit daripada isolat jamur wildtype. Dengan demikian isolat jamur mutan ini memiliki peluang yang lebih rendah 
dalam menginfeksi inangnya dibandingkan dengan isolat jamur wildtype. Menurut Prayogo (2013), semakin tinggi kerapatan spora, maka semakin tinggi pula peluang kontak antara patogen dengan inang. Apakah peluang kontak ini mempengaruhi virulensi? Atau, dengan kerapatan spora yang sama (peluang kontak sama), betulkah isolat jamur mutan $B$. bassiana akan sama virulensinya dengan isolat jamur wildtype B. bassiana?

Tabel 4 menunjukkan virulensi isolat mutan dan wildtype jamur B. bassiana setelah diinokulasikan pada hama $R$. linearis. Kerapatan spora yang diinokulasikan tidak berbeda nyata antar isolat. Isolat jamur Bbyf22 (mutan) dan isolat jamur Bbyf24 (mutan) membutuhkan 3,7 hari dan 4,9 hari untuk menimbulkan kematian pada $R$. linearis. Isolat jamur Bbyf (wildtype) membutuhkan waktu 3,5 hari untuk menimbulkan kematian pada $R$. linearis (Tabel 4). Hasil penelitian inimenunjukkan bahwa virulensi jamur B. bassiana mutan terhadap $R$. linearis tidak berbeda (Bbyf22) atau lebih rendah (Bbyf24) daripada virulensi jamur B. bassiana wildtype (Bbyf).

\section{KESIMPULAN}

Dari hasil penelitian dapat diambil kesimpulan sebagai berikut: 1) Isolat Bbyf22 dan Bbyf24 (mutan) mampu tumbuh dan berkembang dengan normal seperti isolat Bbyf(wildtype). Pertumbuhan diameter dan daya berkecambah (viabilitas) isolat Bbyf22 dan isolat Bbyf24 (mutan) relatif sama dan tidak berbeda nyata dibandingkan dengan isolat Bbyf (wildtype) tetapi kerapatan spora isolat jamur mutan (Bbyf24 dan Bbyf22) lebih rendah daripada kerapatan spora isolat jamur wildtype (Bbyf), 2) Jamur B. bassiana terbukti virulen terhadap hama $R$. linearis dengan $\mathrm{LT}_{50}=3,7$ hari (isolat Bbyf22, mutan); 4,9 hari (isolat Bbyf24, mutan); dan 3,5 hari (isolat Bbyf, wildtype).

\section{DAFTAR PUSTAKA}

Asadi. 2009. Identifikasi ketahanan sumber daya genetik kedelai terhadap hama pengisap polong. Balai Besar Penelitian dan Pengembangan Bioteknologi dan Sumberdaya Genetik Pertanian. Buletin Plasma Nutfah. 15(1): 17-23.

Atman, R. 2012. Rancang bangun program aplikasi sistem pakar untuk diagnosis hama utama kedelai. Informatika Pertanian. 21(1): 11-26.

Avanti, B., K. Balaraman \& R. Gopinath. 2014. Development of higher temperature tolerant mutant of Beauveria bassiana and Verticillum lecanii. International Journal of Life Sciences Biotechnology and Pharma Research. 3(3): 109-112.

Dwayne, D.H. \& G.G. Khachatourians. 1994. Isolation and characterization lethal mutants of Beauveria bassiana. Journal Microbiology. 40: 766-776.

Fitriana, Y., S. Shinohara, K. Satoh, I. Narumi \& T. Saito. 2014. Benomyl-resistant Beauveria bassiana (Hypocreales: Clavicipitaceae) mutants induced by ion beams. The Japanese Society of Applied Entomology and Zoology. 50: 123129.

Hasibuan, R. 2003. Pengendalian Hama Terpadu. Universitas Lampung. Bandar Lampung. 109 hlm. 
Prayogo, Y. 2013. Patogenisitas cendawan entomopatogen Beauveria bassiana (Deuteromycotina: Hyphomycetes) pada berbagai stadia kepik hijau (Nezara viridula L.). Jurnal Hama Penyakit Tumbuhan Tropika. 13(1): 75-86.

Soetopo, D. \& I.G.A.A. Indrayani. 2007. Status teknologi dan prospek Beauveria bassiana untuk pengendalian serangga hama tanaman perkebunan yang ramah lingkungan. Perspektif. 6(1): 29-46. 